\title{
TOWARD A DRIVING COMPETENCY ASSESSMENT ENCOURAGING ELDERLY'S AUTOMOBILITY: A FRENCH POINT OF VIEW
}

\author{
Catherine Gabaude, Laurence Paire-Ficout \\ INRETS - LESCOT \\ BRON Cedex, France \\ E-mail: catherine.gabaude@inrets.fr, laurence.paire-ficout@inrets.fr
}

\begin{abstract}
Summary: The purpose of this paper is to suggest a methodology for approaching French elderly driver assessments. More precisely, the objective is to evaluate the impact of visual and cognitive declines in older drivers on real road driving performances. A case control study was conducted with 40 senior drivers (aged between 61 to 80 years old) recruited via their insurance company: 20 case volunteers who had caused 3 or more accidents during a three-year period and 20 control volunteers who had caused no accidents during the same period. The experiment consisted of non-driving laboratory tests, including visual and cognitive tests, and a driving assessment in a real traffic situation. Results showed that, compared to the control group, elderly drivers with a history of accidents, have poorer performance on the cognitive tests. Moreover, data from the multiple regression analysis showed that the two measures entering the model were Zazzo time and movement perception (age and group being controlled). Some considerations that shape construction of a driving assessment are discussed. We discuss the fact that such an approach can be used to estimate the driving skills of drivers, not to deliver an aptitude or inaptitude certificate, but to adapt the advice given to drivers.
\end{abstract}

\section{INTRODUCTION}

With regard to elderly drivers, all population forecasts in industrialized countries agree upon the fact that this part of the population is growing rapidly, due to demographic and cultural reasons. Strategies, policies and provision of services must be reconsidered in order to support the continued health and well-being of the elderly. To accord mobility and safety issues for elderly drivers, a compromise must be reached between too great a reduction in mobility (which will consequently increase the number of people becoming dependant in particular cases) and an increase in road insecurity (Alsnih \& Hensher, 2003).

The aging process is associated with a more or less severe modification of functional abilities. Impairments can be observed at sensory-motor and/or cognitive levels (Eby et al., 1998; Gabaude, 2003). Because of these varying levels of functional abilities, it is increasingly difficult to identify who is at risk and to propose subsequent remediary actions.

Some countries impose a medical assessment at around 70 to evaluate the ability to drive. Today, in France, neither measure exists. The need for screening elderly drivers is questionable, if it only deals with medical aspects (Hakamies-Blomqvist, 1996). It seems that a more comprehensive approach should be adopted to improve our knowledge of the impact of functional ability impairment on driving competency. The purpose of this paper, therefore, is first, to explore the link between the functional ability measured by laboratory non-driving tests 
and the driving ability measured by an on-road test, and second, to propose an assessment methodology based on reliable and well tailored tools. Previous research studies have already adopted an analytical approach that underlines the relationship between visual and/or cognitive functions and the driving skills. Such studies observed that drivers who scored in the lowest 10 $\%$ on the cognitive tests were approx 1.5 times more likely to be in crashes than were drivers who scored in the highest $10 \%$. The results obtained by C. Lundberg et al. (1997) and K. Ball et al. (1998) support the idea that visual and cognitive function decrements constitute an important causal factor in the crashes of older drivers. McKnight \& McKnight (1999) found a significant correlation between unsafe driving incidents and deficiencies in attentional, perceptual, cognitive, visual and psychomotor categories. In the same way, Daigneault et al. (2002b) indicated that, compared to the control group, elderly drivers with a history of accidents, have poorer performance on the cognitive measurements. De Raedt \& Ponjaert-Kristoffersen (2000b) also found correlations between clinical measures (physical, visual, cognitive) and performance in the road test.

In-car observation methodology is sometimes used in order to establish the likely effects of invehicle information systems on driving performance. Risser (1985) studied the behavior in traffic conflict situations and developed an in-car observation method in order to collect standardized variables and free observation. The question of the reliability and validity of the performancebased driving evaluation is often explored (De Raedt \& Ponjaert-Kristoffersen, 2001; Odenheimer et al., 1994). Results from Hjalmdahl (2004) indicate that in-car observation is a reliable and valid method to observe driver behavior (due to the possibility of training observers to perform observations satisfactorily and to the consistency of driver speed choice). Many authors are now conducting experimental research around the structuring of on-road evaluation dedicated to driving assessment.

In Staplin et al. (1998), interesting guidelines are delivered in an annotated research compendium of driver assessment techniques for age-related functional impairments. Given that an in-depth analysis of the driving activity of the elderly is useful to study driving abilities, an in-car observation methodology was developed. To pre-test the driving grid, a pilot study was conducted. The objective was to evaluate the impact of visual and cognitive declines on real-road driving performance focusing firstly on driving skills and fitness to drive. A test battery, which included brief and inexpensive tests, was used to define functional ability or to identify impairments in relation to the driving. As in the Janke (2001) study, the objective of this first screening procedure is to determine if the functional abilities of a driver must be explored further through more intensive testing, or if the driver is required to take a road-test. The objective is also to identify tests that are shown to predict driving-related variables on crash involvement. Automobile insurance claims files were used to find a sample of drivers who had caused more than three accidents during a certain period and a sample of control drivers. It is important to note that this research does not claim that accidents are considered as a definitional criterion of unsafe driving. The insurance company data provided a reliable sample of people with heterogeneous driving habits to look for more valid criterions. 


\section{METHOD}

A case control study was conducted with senior drivers (60 years old and more). The study was approved by the French human research ethics committee. This study is concerned with the effects of normal aging on driving; only people without diagnosed neurological pathologies were included in the sample.

\section{Participants}

Two databases collected in a region near Lyon (France) were sent by an insurance company. The first one concerned 3,578 minor insurance claims (less than $€ 10,000$, in order not to call up painful events) that had occurred during the last three years (representing 1,372 members), and the second one consisted of 7,021 members who were claim-free during the same period. Forty senior drivers (aged between 61 and 80 years old) were recruited for the real road experiment. They were still driving at the time of the study, traveling more than 3,000 km per year. Matching parameters between the two groups were the sex, the age and the study level. Twenty subjects (mean age $=66.5, \mathrm{SD}=5.24$ ) were case volunteers who had caused 3 or more accidents during a three-year period (between 1998 and 2000) and 20 subjects (mean age $=65.6, \mathrm{SD}=4.74$ ) were control volunteers with no accident record during the same period.

\section{Procedure}

People were contacted by phone and responded to some information to check if inclusion criteria were correct (still driving at the time of the study, traveling more than 3,000 km per year, driving without an automatic transmission). Then an appointment for the experiment was arranged and a questionnaire, which covered the driving history and the accident record, was sent two weeks before the appointment. The evaluation started with the visual tests or the medical exam. Then, the neuropsychological assessment procedure was carried out. As the last step of the day, the road test was proposed. Assessment of each individual took approximately three hours (more when the adaptation period to an unfamiliar vehicle was long).

\section{Non-driving tests}

Non-driving tests, which took about 30 minutes to complete, included visual tests carried out with the "Ergovision" testing device. All tests are carried out in binocular vision: Static visual acuity in far vision, Low-contrast vision and Movement perception. The neuropsychological examination consisted of tests chosen with the double aim of detecting severe cognitive impairment and exploring some of the functions altered during the aging process. Three neurospychological tests were used: Mini-Mental Status Evaluation, Zazzo crossing-out test, digit symbol substitution test (WAIS subtest).

\section{Road test}

The driving performance evaluation was conducted along a fixed route (25 km). The participants had to drive a test vehicle. The test times ranged from 35 minutes to 55 minutes, depending on familiarization duration and speed on road. 
Route description. All volunteers had to drive along the same route traveling in and out of town and on motorways. The route was outlined to enable relevant information in different kinds of representative traffic situations (such as entering a roundabout, turning left, changing lanes, and looking for directions). Depending on the route portions, the itinerary was given by the experimenter (guided journey) or the driver had to carry out a destination-finding task (nonguided journey). Indications were given without pointing out relevant infrastructure elements (for example: "as soon as you can, turn left”). The itinerary alternated between main roads and secondary roads to be sure that drivers did not know all the traffic situations traveled through. The structured road test was comprised of specified tasks in which drivers were scored on whether or not they met specific criteria. The participants were assessed at 45 pre-designated check-points on the test route (including four T-junctions, eight left-turns with traffic lights, three left-turns without traffic lights, eight lane changes and six roundabouts). For 19 check points, the driver was also assessed while finding a street using road signs only.

Road test scoring. The driving performance evaluation was carried out in two steps. A road test observation grid was filled out during the experimentation (when it was not possible to do it in real time, videotape was later used to fill out the grid) and then a road test scoring grid was completed. The observation grid was inspired by the Driving Performance Evaluation (DPE) developed by the California DMV in Southern California (Hagge, 1994). The observation sheet for the road test was organised according to the sequence of the course. During the road test the driving evaluator, sitting beside the driver, indicated on the observation sheet when certain structured maneuvers at pre-designated points on the route were not performed. For this type of information the number of possible errors was fixed. A road-test scoring grid was used to ensure uniformity and consistency in the data collection process. The dependant variable studied was a penalty score. It was defined as the total number of possible errors. Weighting of the more dangerous errors (see Table 1) (hazardous or potentially critical) was consistent with the scoring method used by Dobbs (1997). The observation grid consisted of height dimensions. In the road test scoring grid, each dimension was rated on 3-point subscales according to the situations.

Table 1. Information included in the observation and the scoring grids

\begin{tabular}{lc}
\hline Rated dimensions & Penalty (pt) \\
\hline Action & 2 or $1^{*}$ \\
\hline Mirror check: not done & 0,5 \\
Mirror check: late & 2 \\
Visual search: not done & 1 \\
Visual search: incomplete & 0.5 \\
Visual search: late & 1 \\
Indicator use: absent & 0,25 \\
Indicator use: late & 1 \\
Lane choice: error & 3 or less** \\
Violation & 2 \\
Positioning at intersection: dangerous & 0,5 \\
Positioning at intersection: in the way &
\end{tabular}

* Only one point if a road separator exists, in the other case, a two-wheeled vehicle might be present.

**According to the situation, 1.5 point was attributed when the maneuver was judged hazardous. 
Analysis. Several analyses were conducted such as t-test and correlation to describe the data and make preliminary inferences. The study’s main task was to distinguish the subject group and predict the road test score. A multiple regression analysis was conducted to predict the driving penalty score from non-driving test measures.

\section{RESULTS}

\section{Visual tests}

The number of subjects having or not having the visual acuity required by the French driving legislation is presented in Table 2 . Three of the 40 individuals were driving with poor visual acuity. The difference between the two groups was not significant for the movement perception test and for the contrast vision test (Table 2). For the contrast vision test, the score recommended by the Ergovision handbook indicated that only one control subject had good contrast vision; all others had a poor contrast vision.

\section{Neuropsychological tests}

Only one neuropsychological test (digit symbol scoring) showed a significant difference between case and control group. This indicated that the control subjects have a less important cognitive and motor slowing down than case subjects.

Table 2. Non-driving and driving tests scores for case and control groups

\begin{tabular}{|c|c|c|c|}
\hline & $\begin{array}{l}\text { Case } \\
n=20\end{array}$ & $\begin{array}{c}\text { Control } \\
n=20\end{array}$ & $\mathrm{p}=$ \\
\hline \multicolumn{4}{|l|}{ Visual tests } \\
\hline \multicolumn{4}{|l|}{ Acuity (n) } \\
\hline Far vision acuity inferior or equal to $4 / 10$ & 2 & 1 & \\
\hline Far vision acuity superior to $4 / 10$ & 18 & 19 & \\
\hline Movement perception $\quad m(s d)$ & $10,05(1,10)$ & $10,35(1,09)$ & 0,391 \\
\hline Contrast vision m (sd) & $3,90(2,08)$ & $3,25(2.57)$ & 0,385 \\
\hline \multicolumn{4}{|l|}{ Cognitive tests m (sd) } \\
\hline MMSE & $28,30(1,42)$ & $27,85(1,39)$ & 0,317 \\
\hline Zazzo good stimuli crossed-out & $28,25(0,97)$ & $27,75(2,02)$ & 0,325 \\
\hline Zazzo time & $56,05(9,29)$ & $49,80(12,98)$ & 0,088 \\
\hline Digit symbol test & $44,65(9,08)$ & $50,90(8,26)$ & 0,029 \\
\hline \multicolumn{4}{|l|}{ Road test score m (sd) } \\
\hline Total score & $38,87(14,55)$ & $29,55(10,80)$ & 0,027 \\
\hline Guided score & $20,57(8,78)$ & $14,24(6,16)$ & 0,012 \\
\hline Non guided score & $17,98(7,84)$ & $15,62(6,92)$ & 0,319 \\
\hline Violation score & $2,93(3,72)$ & $0,85(1,32)$ & 0,027 \\
\hline \multicolumn{4}{|l|}{ Violation encountered $\left(\mathrm{N}^{\circ}\right)$} \\
\hline Traffic light & 5 & 0 & \\
\hline Priority & 3 & 0 & \\
\hline Left turn with traffic light & 9 & 4 & \\
\hline Left turn without traffic light & 3 & 1 & \\
\hline
\end{tabular}




\section{Road test scores}

To evaluate the interrater reliability of the evaluation grid, the penalty scores rated by the examiner were rated a second time by another person using the grid and the video. A significant correlation was observed between the two scores $($ Rho $=0.928, \mathrm{p}<0.001)$.

The road test scores were globally analyzed at first. No significant difference $(\mathrm{p}=0.544)$ was observed on the penalty score between men (mean=32.83, SD=15.54) and women (mean=35.48, $\mathrm{SD}=11.59)$, and the study level was not correlated with the penalty score $(r=-0,092, p=0,572)$.

\section{Differences between case and control group}

Significant differences are observed between case and control group for the total score and for the guided score, with case individuals having a higher mean penalty score. When drivers were asked to choose their way by reading road signs, the penalty score was not significantly different between the two groups. Case individuals seemed to be more cautious in this situation. An analysis of the subtotals of the six rated dimensions (mirror check, visual search, indicator use, lane choice, violation, positioning at intersection) showed only a significant difference between Case and Control on violation criteria. Twenty violations were observed in the case group and 5 in the control group. For the two groups, violations were observed for left turn intersections more frequently. For the other dimensions, the difference between case and control groups was not significant. Nevertheless, for all drivers on average, most of the penalty points were attributed as followed: $29 \%$ of penalty point for visual search, $24 \%$ for mirror checking, $24 \%$ for indicator use, $14 \%$ for lane choice, $6 \%$ for violation and $5 \%$ for positioning at intersection.

Since the adoption of a yield-at-entry regulation in 1966 by Great Britain and in 1983 by France, the superior safety record of modern roundabouts was well-known in western Europe and in most British-influenced countries (Dearagao, 1992). Even if roundabouts are safer and more efficient intersections for drivers in general, in France, not all elderly drivers are accustomed to them. A subtotal of the penalty score was calculated for the roundabouts and the difference between case and control was not significant. Nevertheless for the 45 check points on the test route, ten were located on roundabouts. On average, $34 \%$ of the penalty points were attributed to errors happening in such a situation.

\section{Predicting road test performance}

Results recorded from all drivers are included in the analysis. Table 3 shows the correlation coefficients between non-driving measures and penalty score ( $r$ and $p$ ) and multiple regression analysis results $(\beta, p)$. Since the number of observations was relatively low (40) the decision was taken to integrate only five variables in the model to be sure that the estimates of the regression line would be quite stable and replicable. Age and group were not removed to enter these variables in the model and the more correlated variables were also entered (movement perception, digit symbol and Zazzo time). Independent variables were removed one at a time according to the effect on the regression coefficient.

It can be observed that the age factor is associated with the penalty score, meaning that the penalty score of older drivers is higher than the others. All visual tests are correlated with the 
penalty score. Moreover, with regard to cognitive status of drivers, participants with lower scores in the digit symbol test and who needed more time to complete the Zazzo crossing-out task had higher penalty scores.

Table 3. Results from correlation and multiple regression of non-driving measures with penalty scores $(\mathrm{RV}=$ variable removed from the analysis)

\begin{tabular}{lcccc}
\hline & $r$ with penalty score & $p=$ & $\beta$ & $p=$ \\
\hline General m (sd) & & & & \\
Age & 0,409 & $\mathbf{0 , 0 0 9}$ & 0,545 & 0,169 \\
Group & & & 5,251 & 0,150 \\
Visual status m (sd) & & & \\
Visual acuity in far vision & $-0,315$ & $\mathbf{0 , 0 4 8}$ & $\mathrm{RV}$ & $\mathrm{RV}$ \\
Movment perception & $-0,385$ & $\mathbf{0 , 0 1 4}$ & $-3,050$ & 0,085 \\
Contrast vision & $-0,317$ & $\mathbf{0 , 0 4 6}$ & $\mathrm{RV}$ & $\mathrm{RV}$ \\
\hline Cognitive status m (sd) & & & & \\
MMSE & 0,084 & $\mathbf{0 , 6 0 7}$ & $\mathrm{RV}$ & $\mathrm{RV}$ \\
Zazzo good stimuli crossed-out & $-0,247$ & 0,124 & $\mathrm{RV}$ & $\mathrm{RV}$ \\
Zazzo time & 0,498 & $\mathbf{0 , 0 0 1}$ & 0,427 & $\mathbf{0 , 0 1 2}$ \\
Digit symbol test & $-0,463$ & 0,003 & $\mathrm{RV}$ & $\mathrm{RV}$ \\
\hline
\end{tabular}

Forty three percent of the variation of the penalty score could be predicted based on age, group and scores obtained with 2 non-driving tests: movement perception and Zazzo time $\left(\mathrm{R}^{2}=43 \%\right.$, $\mathrm{R}^{2}$ adjusted $\left.=36 \%, \mathrm{~F}=6.55, p=.0005\right)$.

\section{DISCUSSION}

The findings of this study confirmed the relationship between visual and/or cognitive functions and the driving skills in function of the number of crashes. As found previously, elderly drivers with a history of accidents have poorer performance on the visual and cognitive measure compared to the control group (Ball et al., 1988; Daigneault et al., 2002a; De Raedt \& PonjaertKristoffersen, 2000a; La Prévention Routière, 1997; C. Lundberg et al., 1997; McKnight \& McKnight, 1999; Stutts et al., 1998). In response to Elliot et Grayson’s remark (Elliott \& Grayson, 2001), that there is a need to clarify the relationship between performance on tests of cognitive ability and driving performance, such a study provides new data.

The need for finding reliable and well tailored tools is also crucial. It is important to keep in mind that assessment tools should be rapid and easy to administer. The results from multiple regression allowed us to demonstrate the relevance of two tests that can be used easily. First, the Zazzo test, which is a cognitive test, can give useful information about attentional and inhibition mechanisms. Some authors have showed that these mechanisms play an important role in driving activities (Lafont \& Laumon, 2003; Marin-Lamellet et al., 2003; Paire-Ficout, 2003). Here, the drivers who had a history of accidents were probably slightly impaired in these attentional processes. In these studies, Zazzo test have already allowed researchers to distinguish two elderly groups: one with normal aging and one in the early stage of dementia of the Alzheimer's type (DAT) (Lafont \& Laumon, 2003; Marin-Lamellet et al., 2003; Paire-Ficout, 2003). Because 
of an increasing prevalence of DAT, and the observation of greater impairment of road skills in subjects with DAT compared with older drivers who were controls (Fox et al., 1997), a systematic emphasis should be given to the detection of severe cognitive impairment in the assessment of older driver fitness. In the present study, the MMS evaluation turned out to be not sufficient to distinguish the elderly drivers who had a history of accidents from the control group. We can hypothesize that the processes measured in this general evaluation are not supposed to be impaired.

The only visual measurement predicting driving performances concerns dynamic vision. Previous studies have already showed this relation between the number of crashes and a lower dynamic perception. This relation showed the importance of taking into account this dimension in a driving assessment procedure for elderly persons. In certain cases, where there is visual decline, there is a need to inform the drivers of the consequences for themselves and how they will cope with these declines in the future. For these reasons, there is a need to introduce standard screening tests that identify drivers suspected of having sensorial deficits and who need to change their behavior or re-learn various skills, or those who are unsafe to continue driving.

The grid developed for the observation of the driving activity appeared to be a useful tool. The type of route used seems to be long and varied enough to allow the evaluation of volunteers' driving skills. Moreover as the interrater reliability is good, the method used is adapted to ensure uniformity in the data collection process and in the scoring techniques.

In the present study, subjects were not driving their own cars, and moreover, they were driving in an unfamiliar sector. This problem was evoked by various authors (De Raedt \& PonjaertKristoffersen, 2001; Catarina Lundberg \& Hakamies-Blomqvist, 2003). It might be interesting to assess the same drivers using their own cars on a current route to see if their driving skills (assessed with the same methodology standardized as much as possible) are altered or not. It is also interesting to observe that elderly drivers encountered difficulties with left turns and in particular left turns with traffic lights. Adapted intersections should be designed so that decisions can be taken sequentially. In general, traffic situations should be as predictable as possible to maximize the opportunity for anticipation by the older drivers. If the infrastructure was more standardized, especially the layout of roundabout and intersections, elderly drivers would be more at ease using them.

\section{CONCLUSION}

Two issues are important to consider with regard to monitoring older drivers: the attempt to identify individuals with an excess risk of accident involvement and the attempt to find ways of maintaining or restoring functional capabilities.The introduction of standard assessment procedures will be particularly necessary for people suspected of having illnesses impacting their driving safety. If in the future a mandatory elderly driver screening is supported, and that may be the case in France in the future because a legislative proposal is under study, such an approach can be used to estimate the driving skills of drivers not to deliver an aptitude or inaptitude certificate but to adapt the advice given to drivers. 


\section{REFERENCES}

Alsnih, R., \& Hensher, D. A. (2003). The mobility and accessibility expectations of seniors in an aging population. Transportation Research Part A: Policy and Practice, 37(10): 903-916.

Ball, K., Owsley, C., Stalvey, B., Roenker, D. L., Sloane, M. E., \& Graves, M. (1998). Driving avoidance and functional impairment in older drivers. Accid Anal Prev, 30(3): 313-322.

Ball, K. K., Beard, B. L., Roenker, D. L., Miller, R. L., \& Griggs, D. S. (1988). Age and visual search: expanding the useful field of view. J Opt Soc Am A, 5(12): 2210-2219.

Daigneault, G., Joly, P., \& Frigon, J. Y. (2002a). Executive functions in the evaluation of accident risk of older drivers. J Clin Exp Neuropsychol, 24(2): 221-238.

Daigneault, G., Joly, P., \& Frigon, J. Y. (2002b). Previous convictions or accidents and the risk of subsequent accidents of older drivers. Accident Analyses and Prevention, 34(2): 257-261.

De Raedt, R., \& Ponjaert-Kristoffersen, I. (2000a). Can strategic and tactical compensation reduce crash risk in older drivers? Age and Ageing, 29(6): 517-521.

De Raedt, R., \& Ponjaert-Kristoffersen, I. (2000b). Fonctionnement cognitif / neuropsychologique, mécanismes de compensation et conduite automobile des personnes âgées.

De Raedt, R., \& Ponjaert-Kristoffersen, I. (2001). Predicting at-fault car accidents of older drivers. Accident Analysis and Prevention, 33(6): 809-819.

Dearagao, P. (1992). Circles and Roundabouts : An historic review. Paper presented at the Actes du séminaire "Giratoires 92," Nantes - France, Oct. 14-16.

Dobbs, A. R. (1997). Evaluating the driving competence of dementia patients. Alzheimer Dis Assoc Disord, 11 Suppl 1: 8-12.

Eby, D., Trombley, D. A., Molnar, L. J., \& Shope, J. T. (1998). The assessment of older drivers'capabilities: A review of the litterature (No. UMTRI-98-24): The University of Michigan.

Elliott, M., \& Grayson, G. (2001). Dementia and driving. Paper presented at the Transed.

Fox, G. K., Bowden, S. C., Bashford, G. M., \& Smith, D. S. (1997). Alzheimer's disease and driving: prediction and assessment of driving performance. J Am Geriatr Soc, 45(8): 949-953.

Gabaude, C. (2003). Exploration des capacites visuelles et attentionnelles des conducteurs ages: Interets et techniques: Exploration of the visual and attentional abilities of elderly drivers: Benefits and techniques. Recherche - Transports - Securite, 81: 165-176.

Hagge, R. A. (1994). The California driver performance evaluation project: an evaluation of a new driver licensing road test (No. 150). Sacramento, CA: California department of motor vehicles.

Hakamies-Blomqvist, L. (1996). Research on older drivers: a review. IATSS Research, 20(1): 91101.

Janke, M. K. (2001). Assessing older drivers: Two studies. Journal of Safety Research, 32(1): 43-74. 
La Prévention Routière. (1997). Etudes sur les stages de sensibilisation aux causes et aux conséquences des accidents de la route organiséres par La Prévention Routière Formation pourune reconstitution partielle ducaptial points initial du permis de conduire.

Lafont, S., \& Laumon, B. (2003). Vieillissement et gravite des atteintes lesionnelles des victimes d'accident de la circulation routiere: Ageing and injury severity among road traffic accident victims. Recherche - Transports - Securite, 79-80: 121-133.

Lundberg, C., \& Hakamies-Blomqvist, L. (2003). Driving tests with older patients: effect of unfamiliar versus familiar vehicle. Transportation Research Part F: Traffic Psychology and Behaviour, 6(3): 163-173.

Lundberg, C., Johansson, K., Ball, K., Bjerre, B., Blomqvist, C., Braekhus, A., et al. (1997). Dementia and driving: an attempt at consensus. Alzheimer Dis Assoc Disord, 11(1): 28-37.

Marin-Lamellet, C., Paire-Ficout, L., Lafont, S., Amieva, H., Laurent, B., Thomas-Anterion, C., et al. (2003). Mise en place d'un outil d'evaluation des deficits attentionnels affectant les capacites de conduite au cours du vieillissement normal et pathologique: L'etude SEROVIE : The creation of a tool for evaluating attentional deficits that affect driving skills during normal and pathological ageing: The SEROVIE study. Recherche - Transports - Securite, 81: 177-189.

McKnight, A. J., \& McKnight, A. S. (1999). Multivariate analysis of age-related driver ability and performance deficits. Accid Anal Prev, 31(5): 445-454.

Odenheimer, G. L., Beaudet, M., Jette, A. M., Albert, M. S., Grande, L., \& Minaker, K. L. (1994). Performance-based driving evaluation of the elderly driver: safety, reliability, and validity. J Gerontol, 49(4): M153-159.

Paire-Ficout, L. (2003). Maladie d'Alzheimer, déficits attentionnels et conduite automobile. Revue neurologique, 79.

Staplin, L., Lococo, K. H., Steward, J., \& Decina, L. E. (1998). Safe mobility for older people notebook. Kulpsville: The Scientex Corporation.

Stutts, J. C., Stewart, J. R., \& Martell, C. (1998). Cognitive test performance and crash risk in an older driver population. Accid Anal Prev, 30(3): 337-346. 